\title{
Effect of Vitamin D3 Supplementation on Fasting Plasma Glucose, Insulin Resistance and Lipid Profile in Women with Gestational Diabetes Mellitus: A Double-blind Randomized Controlled Clinical Trial
}

\section{Kimia Sedighi}

Student Research Committee, Faculty of Medicine, Hormozgan University of Medical Sciences, Bandar Abbas, Iran

\section{Roghayeh Shahbazi}

Department of Cellular and Molecular Medicine, University of Ottawa, Ottawa, Canada

\section{Elham Boushehri}

Department of Health Services, Faculty of Health, Hormozgan University of Medical Sciences, Bandar Abbas, Iran

\section{Ghazal Zoghi}

Cardiovascular Research Center, Hormozgan University of Medical Sciences, Bandar Abbas, Iran

Mahmood Khayatian

Department of Biochemistry, Faculty of Medicine, Hormozgan University of Medical Sciences, Bandar Abbas, Iran

\section{Somayeh Kheirandish}

Endocrinology and Metabolism Research Center, Hormozgan University of Medical Sciences, Bandar Abbas, Iran

Masoumeh Kheirandish ( $\nabla$ kheirandishm@yahoo.com )

Hormozgan University of Medical Sciences https://orcid.org/0000-0002-7355-4456

Research article

Keywords: vitamin D, gestational diabetes, insulin resistance, HOMA-IR

Posted Date: August 13th, 2020

DOI: https://doi.org/10.21203/rs.3.rs-56785/v1

License: (c) (i) This work is licensed under a Creative Commons Attribution 4.0 International License. Read Full License 


\section{Abstract}

Background: There is inconsistent data on the effects of vitamin D supplementation on metabolic profiles in pregnant women with gestational diabetes mellitus (GDM). The aim of the current study was to assess the effect of vitamin D supplementation on the glycemic and metabolic status of pregnant women with GDM.

Methods: In this randomized double-blind controlled trial pregnant women with GDM referred to the Diabetes Clinic of Hormozgan University of Medical science, Bandar Abbas, 2016-2017, were randomly assigned to the intervention $(n=25)$ and placebo $(n=25)$ groups. Subjects in the intervention group received two $50000 \mathrm{IU}$ vitamin $\mathrm{D}_{3}$ pearls (at baseline and at day 21) plus $1000 \mathrm{mg}$ calcium daily, and those in the placebo group received 2 placebos at the same times and $1000 \mathrm{mg}$ calcium daily. Fasting blood samples were collected at baseline and after 6 weeks for the measurement of lipid profile, fasting plasma glucose (FPG), insulin, 25-hydroxy vitamin D, calcium, and phosphorus. Homeostatic model assessment for insulin resistance (HOMA-IR) was calculated.

Results: Serum 25-hydroxy vitamin D significantly increased in the intervention group $(P<0.001)$. Vitamin D supplementation significantly decreased FPG $(P=0.049)$, serum insulin level $(P=0.001)$, and HOMA-IR $(P=0.001)$ in the intervention group compared to the placeb group. Furthermore, vitamin $D$ significantly reduced serum triglyceride $(P=0.0 .002)$, whereas it had no significant effect on total cholesterol $(P=0.099)$, low-density lipoprotein cholesterol $(L D L-C)(P=0.279)$, and high-density lipoprotein cholesterol (HDL-C) $(\mathrm{P}=0.472)$ compared to the placebo group.

Conclusions: Vitamin D supplementation can be beneficial in the regulation of FPG, insulin level, and HOMA-IR in pregnant women with GDM.

Trial registration: The research has retrospectively been registered at the Iranian Registry of Clinical Trials (IRCT) with the registration number: IRCT20150607022585N3 and is accessible at the following website: www.irct.ir.

\section{Background}

Gestational diabetes mellitus (GDM) is a common metabolic disorder of pregnancy and is defined as any degree of glucose intolerance diagnosed for the first time during pregnancy (1). GDM accounts for roughly $90 \%$ of the total cases of diagnosed diabetes in pregnant women (2). The prevalence of GDM is constantly increasing, possibly due to the increase in maternal age and weight (1). The prevalence of this disorder is estimated between 1 and $14 \%$ throughout the world. This variation might stem from using various screening criteria and diagnostic tests, as well as the difference in individual characteristics such as age and pre-pregnancy body mass index $(\mathrm{BMI})(1,3)$. Age over 25 years, obesity, history of macrosomia, history of GDM in previous pregnancies, gestational hypertension, family history of type 2 diabetes, and ethnicity are primary risk factors of $\operatorname{GDM}(4,5)$. 
GDM is associated with several short-term maternal and perinatal complications, also long-term consequences for both mothers and their offspring $(6,7)$. The short-term adverse outcomes for mothers are the increased risk of preeclampsia, urinary tract infection, and cesarean section. In addition, the increased future risk of type 2 diabetes in approximately $60 \%$ and the risk of GDM recurrence in subsequent pregnancies in more than $40 \%$ in women with a history of GDM, are major long term adverse consequences of GDM for mothers (8-10). Some of the fetal consequences are macrosomia, birth trauma, hypoglycemia and respiratory distress syndrome $(5,11)$ and offspring long-lasting adverse health complications are type 2 diabetes, obesity, and neurodevelopmental, neuropsychiatric and ophthalmic problems (4).

Early diagnosis and proper treatment of GDM reduces the risk of its complications (4). The main treatments for GDM include medical and nutritional therapy, physical activity, weight management, hypoglycemic agents, and insulin therapy $(2,12)$.

Pregnancy is accompanied by insulin resistance during the second and early third trimesters resulting in a remarkable increase in insulin secretion $(12,13)$. Increased levels of some hormones including human placental lactogenic hormone, growth hormone, cortisone, estrogen, and progesterone lead to reduced insulin sensitivity (1).

Vitamin D plays a significant direct and indirect role in secretion and function of insulin as well as glucose homeostasis through several mechanisms. Studies show that vitamin D supplementation modifies metabolic status and increases insulin sensitivity in patients with type 2 diabetes (14).

According to studies, the prevalence of vitamin D deficiency is considerable among pregnant women (15, 16), which might increase the risk of GDM. Although the systematic reviews of observational and randomized clinical trial studies showed a significant association between maternal vitamin $D$ deficiency and the GDM occurrence (17-19), there are controversial results in this area. Therefore, the aim of the current study was to investigate the effect of supplementation with vitamin D on glycemic and metabolic status of pregnant women with GDM.

\section{Methods}

\section{Subjects}

This randomized, double-blinded, placebo-controlled clinical trial was conducted in Bandar Abbas, Iran, between the years 2016 and 2017. According to the suggested formula for calculation of sample size for randomized clinical trials, and considering type I error of $5 \%(\alpha=0.05)$ and type II error of $10 \%(\beta=0.10$, power $=90 \%$ ), and using data from a previous study (20), the sample size was calculated as 25 subjects in each group. Subjects were selected from those who were referred to the Diabetes Clinic of Hormozgan University of Medical science, Bandar Abbas, Iran based on the inclusion and exclusion criteria. Inclusion criteria were as follows: pregnant women aged 18-40 years, diagnosis of GDM after the first trimester by the one-step standard diagnostic test (a single 75-g oral glucose tolerance test) according to the 
International Association of the Diabetes and Pregnancy Study Groups (IADPSG) criteria (21), and written informed consent to participate in the study. Whereas, the exclusion criteria were: preeclampsia, insulin therapy, hypothyroidism, urinary tract infection, chronic kidney disease, liver diseases, and smoking. Among 61 referred pregnant women with GDM, 52 eligible patients were invited to take part in the study. Participants were assigned to the intervention $(n=25)$ and control groups $(n=25)$ by computer randomization (fig. 1). The research has retrospectively been registered at the Iranian Registry of Clinical Trials (IRCT) with the registration number: $\underline{\text { IRCT20150607022585N3 }}$ and is accessible at the following website: www.irct.ir.

\section{Intervention}

First, goals, methods, and the stages of the project were fully explained to the participants and written informed consent was obtained from every patient. The duration of the study was 6 weeks for each participant. The intervention group received two vitamin D supplements (D-VIGEL 50000IU CAP, Daana Pharma Co, Iran) at the beginning of the study and 21 days later, along with $1000 \mathrm{mg} / \mathrm{d}$ calcium supplement (Jalinous Pharmaceutical Co, Iran). The control group received two placebo capsules (Daana Pharma Co, Iran) at the same time and $1000 \mathrm{mg} / \mathrm{d}$ calcium supplement (Jalinous Pharmaceutical Co, Iran). In order to modify the effect of diet on study outcomes, all women were consulted by a clinical dietician individually and received personalized diet plans according to their condition. Furthermore, they were asked not to change their daily physical activity.

\section{Variables assessment}

Data on the clinical and gestational status of participants were recorded by an endocrinologist in a checklist. A general information questionnaire was used to collect data on the general characteristics of the attendees. Anthropometric indices including height (without shoes with the precision of $0.5 \mathrm{~cm}$ ), weight (with light clothes and with the precision of $100 \mathrm{~g}$ using Seca scale), BMI (by dividing weight (kg) by height squared $\left(\mathrm{m}^{2}\right)$ was calculated. Fasting blood samples were collected twice (at the study baseline and at the end of the intervention) to measure lipid profile, fasting plasma glucose (FPG), insulin, 25hydroxy vitamin $\mathrm{D}$, calcium, and phosphorus. Commercial kits and chemiluminescent immunoassay technology were applied for the measurement of serum 25-hydroxy vitamin D concentration (DiaSorin Inc, USA) and serum insulin level (DiaSorin Inc, Italy). Fasting plasma glucose (FPG), serum cholesterol, triglyceride, low-density lipoprotein cholesterol (LDL-C), high-density lipoprotein cholesterol (HDL-C), calcium, and phosphorus were measured using commercial kits (Pars Azmun Inc, Iran). Homeostatic Model Assessment of Insulin Resistance (HOMA-IR) was calculated using the suggested formula (22).

\section{Statistical analysis}


Statistical Package for the Social Sciences (SPSS) software (version 25.0, Armonk, NY: IBM Corp.) was used for data analysis. The normality of data distribution was assessed using the Shapiro-Wilks test. To compare quantitative variables which were measured at baseline and the end of the intervention, paired ttest (for data with normal distribution) and Wilcoxon test (for non-normally distributed data) were applied. Independent t-test (for data with normal distribution) and Manne-Whitney test (for non-normally distributed data) were used to compare quantitative variables between two groups. To remove the potential effect of baseline values on our results, the analysis of covariance test was used. P-value $\leq 0.05$ was considered statistically significant.

\section{Results}

During the 6-week follow-up, a subject in the intervention group (due to personal reasons) and a subject in the control group (due to insulin therapy) withdrew from the study. Fifty participants ( $\mathrm{n}=25$ each group) were followed up to the end of week sixth. The mean and standard deviation of the general characteristics of each group is shown in Table 1. No significant differences were found between groups regarding maternal age, gestational age, weight, and BMI at baseline and at the end of the study.

Table 1

General characteristics of participants ${ }^{a}$

\begin{tabular}{|c|c|c|c|}
\hline Variables & $\begin{array}{l}\text { Vitamin D group } \\
(n=25)\end{array}$ & $\begin{array}{l}\text { Placebo group }{ }^{c} \\
(n=25)\end{array}$ & P-value ${ }^{d}$ \\
\hline Maternal Age (year) & $32.24 \pm 3.71$ & $31.52 \pm 6.12$ & 0.618 \\
\hline Pregnancy age (weeks) & $22.55 \pm 6.97$ & $21.52 \pm 7.42$ & 0.705 \\
\hline Height (m) & $158.04 \pm 4.26$ & $158.72 \pm 8.31$ & 0.718 \\
\hline Weight at study baseline $(\mathrm{kg})$ & $68.88 \pm 14.23$ & $69.80 \pm 16.40$ & 0.437 \\
\hline Weight at the end of intervention $(\mathrm{kg})$ & $69.50 \pm 14.82$ & $70.28 \pm 17.5$ & 0.512 \\
\hline BMl at study baseline $\left(\mathrm{kg} / \mathrm{m}^{2}\right)$ & $27.65 \pm 5.10$ & $27.63 \pm 5.8$ & 0.157 \\
\hline $\mathrm{BMl}$ at the end of intervention $\left(\mathrm{kg} / \mathrm{m}^{2}\right)$ & $28.96 \pm 5.88$ & $29.21 \pm 6.27$ & 0.432 \\
\hline \multicolumn{4}{|l|}{ 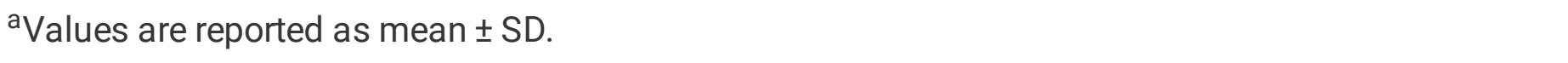 } \\
\hline \multicolumn{4}{|c|}{$\begin{array}{l}{ }^{b} \text { Received } 50,000 \text { IU vitamin } D_{3} \text { twice during the study (at baseline and at day } 21 \text { of study) plus } \\
1000 \mathrm{mg} / \mathrm{d} \text { calcium supplement. }\end{array}$} \\
\hline \multicolumn{4}{|c|}{$\begin{array}{l}\text { 'Received placebo twice during the study (at baseline and at day } 21 \text { of study) plus } 1000 \mathrm{mg} / \mathrm{d} \\
\text { calcium supplement. }\end{array}$} \\
\hline
\end{tabular}


Pre-intervention serum concentration of 25-hydroxy vitamin $D$ was under the normal value in both groups $(13.89 \pm 6.30 \mathrm{ng} / \mathrm{ml}$ in vitamin D group, and $13.23 \pm 8.32 \mathrm{ng} / \mathrm{ml}$ in the placebo group). In addition, a significant difference in serum HDL-C level was found between two groups at the study baseline $(\mathrm{P}<$ $0.001)$; mean serum HDL-C level was significantly higher in the control group $(56.68 \pm 20.98)$ compared to the vitamin $D$ group $(51.20 \pm 8.93)$ (Table 2$)$. 
Table 2

shows the outcomes of the study after the 6-week intervention. Supplementation with 50000 IU

\begin{tabular}{|c|c|c|c|c|c|c|c|}
\hline \multirow[t]{2}{*}{ Variables } & \multicolumn{2}{|c|}{ Vitamin D3 group ${ }^{\mathrm{b}}(\mathrm{n}=25)$} & \multirow[t]{2}{*}{$\mathrm{P} 1^{4}$} & \multicolumn{2}{|c|}{ Placebo group ${ }^{c}(n=25)$} & \multirow[t]{2}{*}{$P 1^{d}$} & \multirow[t]{2}{*}{$P 2^{\mathrm{e}}$} \\
\hline & $\begin{array}{l}\text { Before } \\
\text { intervention }\end{array}$ & $\begin{array}{l}\text { After } \\
\text { intervention }\end{array}$ & & $\begin{array}{l}\text { Before } \\
\text { intervention }\end{array}$ & $\begin{array}{l}\text { After } \\
\text { intervention }\end{array}$ & & \\
\hline $\begin{array}{l}\text { 25-hydroxy } \\
\text { vitamin D } \\
\text { (ng/mL) }\end{array}$ & $\begin{array}{l}13.89 \pm \\
6.30\end{array}$ & $\begin{array}{l}25.92 \pm \\
11.28\end{array}$ & $<.001$ & $\begin{array}{l}13.23 \pm \\
8.32\end{array}$ & $\begin{array}{l}13.95 \pm \\
9.42\end{array}$ & 0.412 & $<0.001$ \\
\hline $\begin{array}{l}\text { FPG } \\
(\mathrm{mg} / \mathrm{dL})\end{array}$ & $\begin{array}{l}88.84 \pm \\
11.31\end{array}$ & $\begin{array}{l}83.96 \pm \\
10.29\end{array}$ & $\begin{array}{l}< \\
0.001\end{array}$ & $\begin{array}{l}85.41 \pm \\
11.80\end{array}$ & $\begin{array}{l}84.64 \pm \\
10.14\end{array}$ & 0.657 & 0.049 \\
\hline $\begin{array}{l}\text { Insulin } \\
(\mu \mathrm{IU} / \mathrm{mL})\end{array}$ & $\begin{array}{l}12.59 \pm \\
5.36\end{array}$ & $9.98 \pm 3.90$ & $\begin{array}{l}< \\
0.001\end{array}$ & $\begin{array}{l}11.11 \pm \\
4.23\end{array}$ & $\begin{array}{l}11.00 \pm \\
4.28\end{array}$ & 0.215 & 0.001 \\
\hline HOMA-IR & $2.72 \pm 1.1$ & $2.01 \pm 0.76$ & $<.001$ & $2.18 \pm 0.92$ & $2.05 \pm 0.80$ & 0.393 & 0.001 \\
\hline $\begin{array}{l}\text { Triglyceride } \\
(\mathrm{mg} / \mathrm{dL})\end{array}$ & $\begin{array}{l}142.40 \pm \\
37.90\end{array}$ & $\begin{array}{l}128.56 \pm \\
28.74\end{array}$ & 0.006 & $\begin{array}{l}134.44 \pm \\
32.51\end{array}$ & $\begin{array}{l}141.26 \pm \\
34.48\end{array}$ & 0.080 & 0.002 \\
\hline $\begin{array}{l}\text { Total } \\
\text { Cholesterol } \\
(\mathrm{mg} / \mathrm{dL})\end{array}$ & $\begin{array}{l}209.40 \pm \\
37.94\end{array}$ & $\begin{array}{l}192.32 \pm \\
37.29\end{array}$ & 0.001 & $\begin{array}{l}218.92 \pm \\
37.22\end{array}$ & $\begin{array}{l}214.12 \pm \\
37.99\end{array}$ & 0.174 & 0.099 \\
\hline $\begin{array}{l}\text { LDL-C } \\
(\mathrm{mg} / \mathrm{dL})\end{array}$ & $\begin{array}{l}129.70 \pm \\
23.96\end{array}$ & $\begin{array}{l}113.60 \pm \\
35.38\end{array}$ & $\begin{array}{l}< \\
0.001\end{array}$ & $\begin{array}{l}135.35 \pm \\
33.13\end{array}$ & $\begin{array}{l}126.12 \pm \\
38.06\end{array}$ & 0.012 & 0.279 \\
\hline $\begin{array}{l}\mathrm{HDL}-\mathrm{C} \\
(\mathrm{mg} / \mathrm{dL})\end{array}$ & $\begin{array}{l}51.20 \pm \\
8.93\end{array}$ & $\begin{array}{l}53.00 \pm \\
8.80\end{array}$ & 0.223 & $\begin{array}{l}56.68 \pm \\
20.98\end{array}$ & $\begin{array}{l}59.72 .60 \pm \\
21.63\end{array}$ & 0.063 & 0.472 \\
\hline $\begin{array}{l}\text { Calcium } \\
(\mathrm{mg} / \mathrm{dL})\end{array}$ & $9.02 \pm 0.35$ & $9.16 \pm 0.39$ & 0.149 & $8.96 \pm 0.41$ & $9.07 \pm 0.33$ & 0.265 & 0.837 \\
\hline $\begin{array}{l}\text { Phosphor } \\
\text { (mg/dL) }\end{array}$ & $3.90 \pm 0.49$ & $3.91 \pm 0.39$ & 0.939 & $3.78 \pm 0.36$ & $3.79 \pm 0.32$ & 0.876 & 0.975 \\
\hline \multicolumn{8}{|c|}{$\begin{array}{l}\text { aValues are reported as mean } \pm \text { SD. HDL-C was significantly different between groups at baseline }(P< \\
0.05) \text {. FPG, Fasting Plasma Glucose; HOMA-IR, Homeostatic Model Assessment of Insulin Resistance }\end{array}$} \\
\hline \multicolumn{8}{|c|}{$\begin{array}{l}\text { beceived } 50,000 \text { IU vitamin } D_{3} \text { twice during the study (at baseline and at day } 21 \text { of study) plus } \\
1000 \mathrm{mg} / \mathrm{d} \text { calcium supplement. }\end{array}$} \\
\hline \multicolumn{8}{|c|}{$\begin{array}{l}\text { CReceived placebo twice during the study (at baseline and at day } 21 \text { of study) plus } 1000 \mathrm{mg} / \mathrm{d} \\
\text { calcium supplement. }\end{array}$} \\
\hline \multicolumn{8}{|c|}{ dP1 value, the difference compared with the value at the beginning of study within groups. } \\
\hline
\end{tabular}

Table 2 shows the outcomes of the study after 6-week intervention. Supplementation with 50000 IU vitamin $D_{3}$ increased the serum concentration of 25-hydroxy vitamin $D$ in the intervention group $(P<$ 
0.001); mean change was significantly different between groups $(P<0.001)$. Besides, the intake of vitamin D3 resulted in a significant decrease in the level of FPG, serum insulin concentration, HOMA-IR, and triglyceride compared to placebo. Although vitamin D3 supplementation caused a significant decline in total cholesterol and LDL-C within the intervention group, mean change of total cholesterol, LDL-C, and HDL-C did not differ significantly between groups. Furthermore, no significant differences were observed in serum calcium and phosphor levels between groups at the end of the study. After adjustment for baseline values, serum concentration of 25-hydroxy vitamin D, FPG, serum insulin concentration, HOMA$I R$, and triglyceride remained significantly different between two groups $(P<0.05)$ (Table 3).

Table 3

Adjusted changes in measured variables in intervention and control groups ${ }^{a}$

\begin{tabular}{|c|c|c|c|}
\hline Variables & Vitamin D Group ${ }^{\mathrm{b}}(\mathrm{n}=25)$ & $\begin{array}{l}\text { Placebo Group } \\
(n=25)\end{array}$ & P-value $^{d}$ \\
\hline 25-hydroxy vitamin $D$ & $12.12 \pm 1.81$ & $0.71 \pm 0.82$ & $<0.001$ \\
\hline FPG & $-4.88 \pm 1.12$ & $-0.76 \pm 1.69$ & 0.041 \\
\hline Insulin & $-2.81 \pm 0.65$ & $-0.09 \pm 0.42$ & 0.002 \\
\hline HOMA-IR & $-0.71 \pm 0.14$ & $-0.08 \pm 0.09$ & 0.002 \\
\hline Triglyceride & $-13.84 \pm 4.4$ & $6.7 \pm 6.25$ & 0.002 \\
\hline Total-Cholesterol & $-17.08 \pm 5.26$ & $-4.80 \pm 3.99$ & 0.056 \\
\hline LDL-C & $-16.11 \pm 5.33$ & $-9.19 \pm 3.36$ & 0.351 \\
\hline HDL-C & $1.80 \pm 1.28$ & $3.04 \pm 1.58$ & 0.366 \\
\hline Calcium & $0.14 \pm 0.09$ & $0.11 \pm 0.09$ & 0.263 \\
\hline Phosphor & $0.008 \pm 0.10$ & $0.12 \pm 0.07$ & 0.313 \\
\hline \multicolumn{4}{|c|}{${ }^{a}$ All values are means \pm SEMs(standard error of mean) adjusted for baseline values. } \\
\hline \multicolumn{4}{|c|}{$\begin{array}{l}\text { beceived } 50,000 \mathrm{IU} \text { vitamin } \mathrm{D}_{3} \text { twice during the study (at baseline and at day } 21 \text { of study) plus } \\
1000 \mathrm{mg} / \mathrm{d} \text { calcium supplement. }\end{array}$} \\
\hline \multicolumn{4}{|c|}{$\begin{array}{l}\text { 'Received placebo twice during the study (at baseline and at day } 21 \text { of study) plus } 1000 \mathrm{mg} / \mathrm{d} \\
\text { calcium supplement. }\end{array}$} \\
\hline dAnalyzed by ANCOVA & & & \\
\hline
\end{tabular}

\section{Discussion}


In the current clinical trial, we evaluated the effect of 50000 IU vitamin D3 supplementation on the metabolic profile of pregnant women with GDM. Vitamin D deficiency is known as a risk factor for diabetes mellitus (23). The positive impact of supplementation with vitamin $D$ on glucose homeostasis is confirmed by in vivo and in vitro studies (24). Observational and cohort studies have demonstrated a negative correlation between serum 25-hydroxy vitamin $D$ and the risk of $\operatorname{GDM}(24,25)$. Evidence shows a higher prevalence of GDM among pregnant women with vitamin D deficiency compared to women with normal serum concentration of 25-hydroxy vitamin D (24). The limited clinical trials that have assessed the effect of vitamin D supplements on glycemic and metabolic status in GDM patients have revealed inconsistent results.

It has been suggested that vitamin D plays a role in the regulation of insulin secretion. Pancreatic beta cells express vitamin $D$ receptors (VDR) and 1-alpha hydroxylase enzyme which shows the functional activity of the active form of vitamin D (1,25-hydroxy vitamin D3) in these cells. 1, 25-hydroxy vitamin D3 binds to VDR on pancreatic beta cells and regulates the intra- and extra-cellular concentration of calcium in beta cells $(23,26)$. Calcium is essential for insulin release $(27)$. Vitamin $D$ can also improve the physiological activity of insulin through the up-regulation of the insulin receptor gene, induction of insulin receptor expression, increase in insulin sensitivity, and insulin-dependent glucose transporter $(26,28)$.

Our results showed that vitamin D3 supplementation reduced the level of FPG, fasting serum insulin, and HOMA-IR in GDM subjects. Some studies have shown the positive effect of vitamin D3 supplementation on the glycemic status similar to our findings. Asemi et al. reported that intake of 50000 IU vitamin D3 (twice a day for six weeks) led to a decrease in FPG in women with GDM. Similar to our study, they also reported a significant decrease in serum insulin and HOMA-IR (25). In a study by Zhang et al., 133 pregnant women with GDM were divided into 4 groups (placebo and low, medium, and high doses of vitamin D). Low, medium, and high doses of vitamin D supplementation did not reduce FPG. Similar to our study, they reported a decrease in serum insulin and HOMA-IR levels in groups receiving medium and high doses of vitamin D supplements (29). In another study, insulin resistance decreased in patients with GDM who received 50000 IU vitamin D, every 2 weeks from the 12th week of pregnancy up to delivery (higher vitamin D3 dose and the duration are comparable with our study) (30).

In our study, vitamin $D_{3}$ consumption also decreased serum triglyceride while could not improve other serum lipid components. Contrary to our findings, Asemi et al., and Zhang et al., reported that cholecalciferol intake decreased the level of total cholesterol; however, it displayed no significant effect on serum triglyceride, LDL-C and HDL-C levels $(25,29)$. Moreover, in a study on overweight and obese participants, intake of cholecalciferol supplement for a period of one year did not reduce any components of the lipid profile (31). Notably, we did not take into account the dietary intake of patients before and after the intervention; the potential differences in dietary intake between the two groups might have affected the results.

In the current study, mean serum 25 -hydroxy vitamin $D_{3}$ was below the normal range $(<30 \mathrm{ng} / \mathrm{dl})$ in both groups at the study baseline, and supplementation with $50000 \mathrm{IU}$ vitamin twice during the study could 
not increase the concentration of serum 25-hydroxy vitamin $D_{3}$ to optimal ranges. Therefore, the ineffectiveness of vitamin $D_{3}$ intake on lipid profile might partly be due to insufficient supplementation. Nevertheless, it improved the glycemic status and insulin resistance index. It appears that even short-term insufficient vitamin D3 doses might have some beneficial effects on GDM .

One of the strengths of the current study was its double-blind randomized design which included pregnant women with different gestational age. Lack of accurate dietary intake assessment, physical activity, and the short duration of intervention are the limitations of our study that it might have negatively impacted our findings regarding the lipid profile. The researchers did not observe any side effects in participants.

\section{Conclusions}

In conclusion, our investigation showed that vitamin $\mathrm{D}_{3}$ supplementation was effective in the improvement of metabolic profile and triglyceride level in GDM patients; however, it did not result in reduction of other components of the lipid profile. Hence, further studies are suggested with longer duration, different doses of vitamin D3 supplementation, and in different ethnic groups to reach consistent results.

\section{Abbreviations}

- BMI: body mass index

- FPG: fasting plasma glucose

- GDM: gestational diabetes mellitus

- HDL-C: high-density lipoprotein cholesterol

- HOMA-IR: homeostatic model assessment for insulin resistance

- LDL-C: low-density lipoprotein cholesterol

- VDR: vitamin D receptor

\section{Declarations}

\section{Ethics approval and consent to participate}

The study received ethics approval from the Ethical Committee of Hormozgan University of Medical Sciences under the ethics code: HUMS.REC.1394.026 and it complies with the statements of the Declaration of Helsinki.

\section{Availability of data and materials}


The datasets used and/or analyzed during the current study are available from the corresponding author on reasonable request.

\section{Competing interests}

The authors declare that they have no competing interests.

\section{Acknowledgments}

Special thanks to the staff of the Diabetes Clinic, Hormozgan University of Medical Sciences, Bandar Abbas, Iran. We are sincerely thankful to our counsellors in the Clinical Research Development Center of Shahid Mohammadi Hospital.

\section{Funding}

This study was supported by grant \#94105 from Hormozgan University of Medical Sciences, Bandar Abbas, Iran.

\section{Author's contributions}

KS designed the study. RS explained the aims of the study, invited the patients to participate, and collected the results. MK was consulted on the appropriate laboratory tests and coordinated the laboratory personnel. SK collected blood samples and performed the laboratory tests. EB determined the sample size and analyzed the acquired data. GZ interpreted the analyzed data and MK wrote the manuscript. All authors read and approved the final manuscript.

\section{References}

1. Duman NB. Frequency of gestational diabetes mellitus and the associated risk factors. Pakistan journal of medical sciences. 2015;31(1):194.

2. Kelley KW, Carroll DG, Meyer A. A review of current treatment strategies for gestational diabetes mellitus. Drugs in Context. 2015;4:212282.

3. Hunt KJ, Schuller KL. The increasing prevalence of diabetes in pregnancy. Obstet Gynecol Clin N Am. 2007;34(2):173-99.

4. Farahvar S, Walfisch A, Sheiner E. Gestational diabetes risk factors and long-term consequences for both mother and offspring: a literature review. Expert Review of Endocrinology \& Metabolism. 2018:1-12.

5. Ural SH, Repke JT. Gestational diabetes mellitus. Reviews in Obstetrics Gynecology. 2008;1(3):129. 
6. Damm P, Houshmand-Oeregaard A, Kelstrup L, Lauenborg J, Mathiesen ER, Clausen TD. Gestational diabetes mellitus and long-term consequences for mother and offspring: a view from Denmark. Diabetologia. 2016;59(7):1396-9.

7. Metzger BE, Contreras M, Sacks DA, Watson W, Dooley SL, Foderaro M, et al. Hyperglycemia and adverse pregnancy outcomes. New England journal of medicine. 2008;358(19):1991-2002.

8. Noctor E, Dunne FP. Type 2 diabetes after gestational diabetes: The influence of changing diagnostic criteria. World Journal of Diabetes. 2015;6(2):234-44.

9. Getahun D, Fassett MJ, Jacobsen SJ. Gestational diabetes: risk of recurrence in subsequent pregnancies. American journal of obstetrics gynecology. 2010;203(5):467. e1-. e6.

10. Kwak SH, Kim HS, Choi SH, Lim S, Cho YM, Park KS, et al. Subsequent pregnancy after gestational diabetes mellitus: frequency and risk factors for recurrence in Korean women. Diabetes Care. 2008.

11. Gasim T. Gestational diabetes mellitus: maternal and perinatal outcomes in 220 Saudi women. Oman medical journal. 2012;27(2):140.

12. Association AD. 13. Management of diabetes in pregnancy: Standards of Medical Care in Diabetes2018. Diabetes Care. 2018;41(Supplement 1):S137-S43.

13. Law KP, Zhang $\mathrm{H}$. The pathogenesis and pathophysiology of gestational diabetes mellitus: Deductions from a three-part longitudinal metabolomics study in China. Clin Chim Acta. 2017;468:60-70.

14. Alvarez JA, Ashraf A. Role of Vitamin D in Insulin Secretion and Insulin Sensitivity for Glucose Homeostasis. International Journal of Endocrinology. 2010;2010:351385.

15. Vandevijvere S, Amsalkhir S, Van Oyen H, Moreno-Reyes R. High prevalence of vitamin D deficiency in pregnant women: a national cross-sectional survey. PloS one. 2012;7(8):e43868.

16. Kazemi A, Sharifi F, Jafari N, Mousavinasab N. High prevalence of vitamin D deficiency among pregnant women and their newborns in an Iranian population. Journal of women's health. 2009;18(6):835-9.

17. Poel YHM, Hummel P, Lips P, Stam F, Van Der Ploeg T, Simsek S. Vitamin D and gestational diabetes: a systematic review and meta-analysis. European journal of internal medicine. 2012;23(5):465-9.

18. Nargesi S, Ghorbani A, Shirzadpour E, Mohamadpour M, Mousavi SF, Amraei M. A systematic review and meta-analysis of the association between vitamin $D$ deficiency and gestational diabetes mellitus. Biomedical Research Therapy. 2018;5(3):2078-95.

19. Rodrigues MRK, Lima SAM, Mazeto GMFdS, Calderon IMP, Magalhães CG, Ferraz GAR, et al. Efficacy of vitamin D supplementation in gestational diabetes mellitus: Systematic review and meta-analysis of randomized trials. PloS one. 2019;14(3):e0213006.

20. Hosseinzadeh-Shamsi-Anar M, Mozaffari-Khosravi H, Salami M-A, Hadinedoushan H, Mozayan MR. The efficacy and safety of a high dose of vitamin $d$ in mothers with gestational diabetes mellitus: a randomized controlled clinical trial. Iranian journal of medical sciences. 2012;37(3):159. 
21. Diabetes IAo, Panel PSGC. International association of diabetes and pregnancy study groups recommendations on the diagnosis and classification of hyperglycemia in pregnancy. Diabetes Care. 2010;33(3):676-82.

22. Pisprasert V, Ingram KH, Lopez-Davila MF, Munoz AJ, Garvey WT. Limitations in the use of indices using glucose and insulin levels to predict insulin sensitivity: impact of race and gender and superiority of the indices derived from oral glucose tolerance test in African Americans. Diabetes care. 2012:DC_120840.

23. Dalgård C, Petersen MS, Weihe P, Grandjean P. Vitamin D status in relation to glucose metabolism and type 2 diabetes in septuagenarians. Diabetes care. 2011:DC_102084.

24. Alzaim M, Wood RJ. Vitamin D and gestational diabetes mellitus. Nutrition reviews. 2013;71(3):15867.

25. Asemi Z, Hashemi T, Karamali M, Samimi M, Esmaillzadeh A. Effects of vitamin D supplementation on glucose metabolism, lipid concentrations, inflammation, and oxidative stress in gestational diabetes: a double-blind randomized controlled clinical trial-. Am J Clin Nutr. 2013;98(6):1425-32.

26. Clark SA, Stumpf WE, Sar M. Effect of 1, 25 dihydroxyvitamin D3 on insulin secretion. Diabetes. 1981;30(5):382-6.

27. Draznin B. Intracellular calcium, insulin secretion, and action. Am J Med. 1988;85(5):44-58.

28. Norman AW, Frankel J, Heldt AM, Grodsky GM. Vitamin D deficiency inhibits pancreatic secretion of insulin. Science. 1980;209(4458):823-5.

29. Zhang Q, Cheng Y, He M, Li T, Ma Z, Cheng H. Effect of various doses of vitamin D supplementation on pregnant women with gestational diabetes mellitus: a randomized controlled trial. Experimental therapeutic medicine. 2016;12(3):1889-95.

30. Soheilykhah S, Mojibian M, Moghadam MJ, Shojaoddiny-Ardekani A. The effect of different doses of vitamin D supplementation on insulin resistance during pregnancy. Gynecol Endocrinol. 2013;29(4):396-9.

31. Jorde R, Sneve M, Torjesen P, Figenschau Y. No improvement in cardiovascular risk factors in overweight and obese subjects after supplementation with vitamin D3 for 1 year. Journal of internal medicine. 2010;267(5):462-72.

\section{Figures}




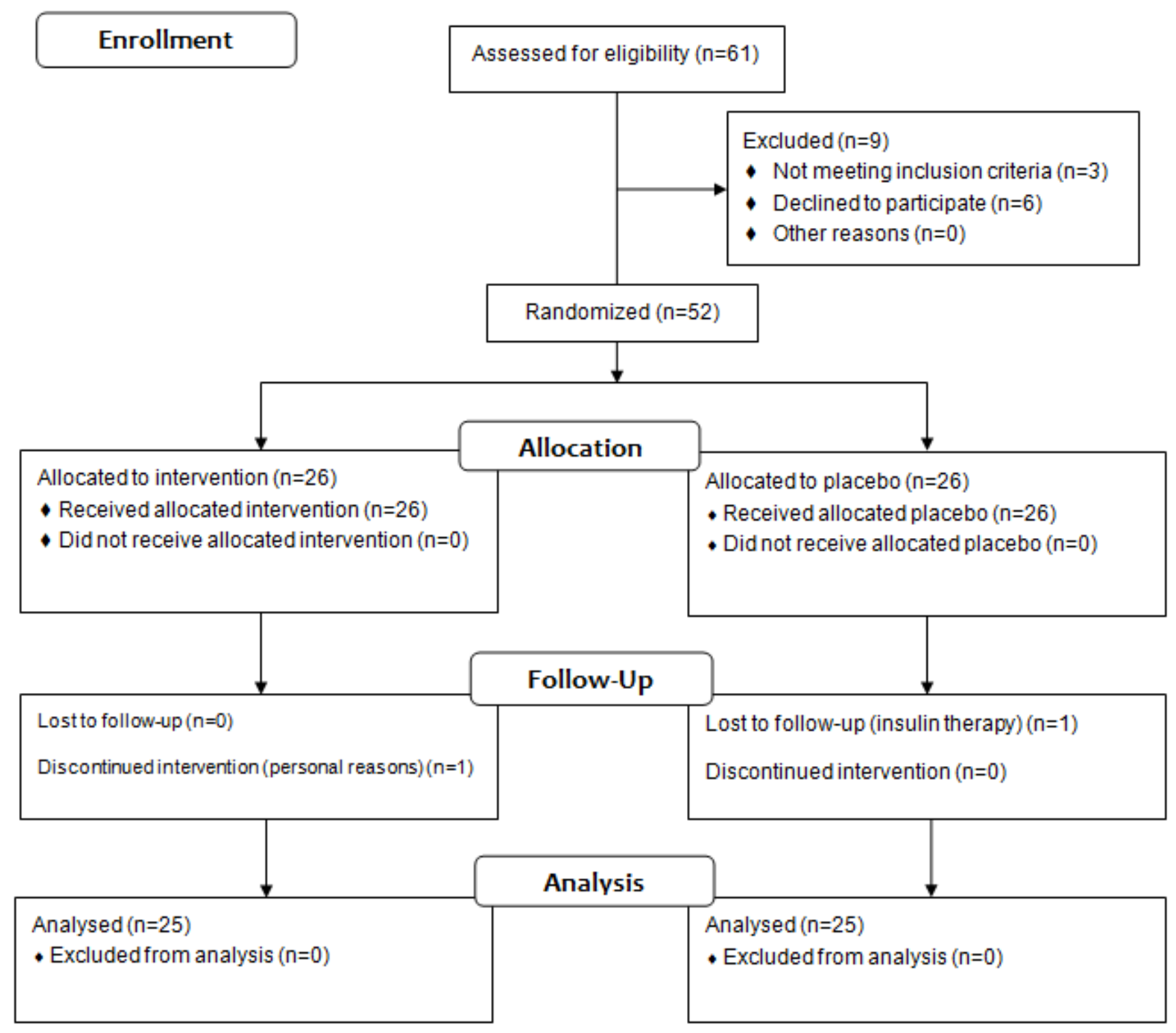

\section{Figure 1}

Flow Diagram 